\title{
DYNAMIC REACTION FORCES OF AN OVERHEAD CRANE ON LIFTING
}

\author{
Bronislovas Spruogis ${ }^{1}$, Arūnas Jakštas ${ }^{2}$, Vytautas Turla $^{3}$, Igor Iljin ${ }^{4}$, Nikolaj Šešok ${ }^{5}$ \\ ${ }^{1}$ Dept of Transport Technological Equipment, Vilnius Gediminas Technical University, \\ Plytines g. 27, LT-10105 Vilnius, Lithuania \\ ${ }^{2}$ Dept of Machine Engineering, Vilnius Gediminas Technical University, \\ J. Basanavičiaus g. 28, LT-03224 Vilnius, Lithuania \\ 3, 4, 5 Dept of Printing Machines, Vilnius Gediminas Technical University, \\ J. Basanaviciaus g. 28, LT-03224 Vilnius, Lithuania \\ E-mails: ${ }^{1}$ bronislovas.spruogis@vgtu.lt; ${ }^{2}$ arunas.jakstas@vgtu.lt; \\ 3vytautas.turla@vgtu.lt (correspondingauthor); ${ }^{4}$ pgilj@vgtu.lt; ${ }^{5}$ pgses@vgtu.lt
}

Received 12 November 2010; accepted 31 July 2011

\begin{abstract}
In the recent period, girder bridge cranes are replaced with double-beam overhead cranes with a rectangular cross-section of the beams. In addition, new materials are used for producing them thus applying other values of allowable loads and deformations. The paper focuses on two overhead cranes working for JSC Vilniaus kranai (Vilnius Cranes). The presented mathematical model provides an opportunity to assess the structural peculiarities of the above introduced cranes. The calculated results of dynamic loads appearing in the beginning and the end of the lifting process and having an impact on the lifting mechanism and metal structure are provided in the article.
\end{abstract}

Keywords: overhead crane, lifting process, dynamic model, stifness of the rope, time diagram.

\section{Introduction}

Overhead cranes are important equipment in the majority of industrial and energy enterprises. The reliability of employing them predetermines a successful manufacturing process. Simultaneously, the introduced equipment is important in respect of occupational safety, thus assessing dynamic load on its operation is an urgent technical problem. Dependently on the dynamic properties of the crane, the parameters of the system for protecting the driver against vibrations and knocks are chosen (Piette, Malchaire 1992).

In respect of dynamic computations, a crane is a united dynamic system that consists of mechanisms, supporting metal structure, drive and a structural unit of the part of the building where the crane operates. An assessment of the variety of all interacting elements of the crane using dynamic computation is too complex; however, it is not required in the majority of cases because not all factors contribute to the formation of dynamic loads to the same extent. When transferring from a real machine to dynamic computation, physical factors that are supposed to be not that important for a specific case of computation are not taken into consideration.

Maximum dynamic loads in the structure of a crane appear in the beginning of the lifting process
(Bogdevičius, Vika 2005) that is attributable to transients in mechanical systems because of rapid changes in resistance and driving forces. In case of such processes, assessing the interaction between the mechanism and its electric engine is of great importance (Augustaitis et al. 2006).

While analyzing electromechanical systems, reliable solutions to the formation of a Simulink-model are obtained in the environment of a MATLAB software package (Gichan et al. 2008; Slivinskas et al. 2010). A dynamic curve of load movement controlled by the crane also has an impact on the loads of its metal structure (Ju et al. 2006).

The load to metal structure is transferred via the rope. On cargo lifting, the stiffness of the rope is growing, and therefore conditions for vibration damping in the rope and the time of transfer of the load from cargo to the lifting mechanism alter (Kaczmarczyk, Ostachowicz 2003). Transferring dynamic loads from the rope to the drum of the lifting mechanism is predetermined by the winding conditions of the rope (Imanishi et al. 2009).

Dynamic deformations and tensions in an overhead crane are calculated applying the method of finite elements upon considering the crane a three-dimensional system. In such a way, loads simultaneously appearing on the vertical and horizontal movement of cargo are 
assessed (Wu 2004). It has been established that when the cargo cradle moves along the overhead crane, the maximum deflection of its beam depends on the speed of the moving cradle (Oguamanam et al. 1998). The obtained dynamic curves of the crane are used for optimizing the structure and drives of the crane (Dyakov, Prentkovskis 2008).

In the recent period, in the course of improvements to automatic welding technologies, more and more widely overhead cranes having the metal structure consisting of two beams with a 'box-type' cross-section are used instead of girder ones used in the previous century. Therefore, the weight of the metal structure is reduced; in addition, dynamic loads caused by the forces of inertia on changes in the speed of the moving crane are also reduced. The mass of a girder crane is approximately equal to that of the lifted cargo, while the mass of a crane with 'box-type' beams is equal to $0.1 \div 0.3$ of the lifted cargo (dependently on the span).

While using such type of cranes (similarly as lorry-mounted cranes where elements with the 'box-type' cross-section were started to apply earlier), the dynamic stability of the structure should be taken into account (Sochacki 2007). The results of calculations obtained while using the software are inspected in the conducted experiments. Thus, the sensibility of the structure to dynamic loads is defined closer (Gottvald 2010), because due to the elasticity of structural elements, vibrations appearing in any part of the structure cause dynamic loads in other parts of it (Bakšys et al. 2009). When using Matlab/Simulink software for simulation purposes, data management and dynamic imitation are applied, dynamic properties of the structure are inspected and its control is simulated (Verdeş et al. 2010).

\section{The Structure, Dynamic Model and Parameters of the Crane}

The paper discusses the dynamics of overhead cranes produced by JSC Vilniaus kranai (Vilnius Cranes) in the beginning of the cargo lifting process when dynamic loads carried in both the drive and metal structure are maximum heavy. The cranes of two types, including TAII-12,5-10,8-6 (crane 1) and TAII-10-20,7-10 (crane 2) with the lifting capacity of 12.5 tons and 10 tons respectively were examined. For producing the above discussed cranes, the types of steel S355J63 or
S355NL (dependently on the ambient temperature) were used, because unlike ordinary structural steel, it causes reduction in the weight of metal structure; however, the impact of inertia forces on cargo increases.

The metal structure of the crane consists of two beams of a rectangular cross-section welded of the plates produced from the above-mentioned steel; the masses of the beams are $1240 \mathrm{~kg}$ and $3420 \mathrm{~kg}$ respectively. The scheme of the crane is provided in Fig. 1. Span $B$ of the first crane equals $10.8 \mathrm{~m}$ and the span of the second crane equals $20.7 \mathrm{~m}$. The lifting mechanism is installed in the trolley where an asynchronous engine equipped with a rope drum connected via a planetary reducer is used; the ratio of the reducer equals 185.3 for both cranes. The repeatability of the system of pulleys equals 6 in the first crane and 4 in the second one. The operational lifting speeds of the cranes are equal to 3.2 and $5.0 \mathrm{~m} /$ minutes respectively.

The dynamic model of the crane under discussion is provided in Fig. 2.

On the basis of the dynamic model of the overhead crane, the expressions of potential and kinetic energy as well as the dissipation function are developed:

$$
\begin{aligned}
& \Pi=\frac{1}{2} \cdot\left(k \cdot\left(x_{2}-\varphi \cdot R+x_{1}\right)^{2}+k_{0} \cdot x_{1}^{2}\right) ; \\
& \mathrm{T}=\frac{1}{2} \cdot\left(m_{0} \cdot \dot{x}_{1}^{2}+m_{2} \cdot \dot{x}_{2}^{2}+I \cdot \dot{\varphi}^{2}\right) ; \\
& \Phi=\frac{1}{2} \cdot\left(h \cdot\left(\dot{x}_{1}-\dot{\varphi} \cdot R+\dot{x}_{2}\right)^{2}+h_{0} \cdot \dot{x}_{1}^{2}\right),
\end{aligned}
$$

where: $x_{0}$ - the deflection of the metal structure; $x_{1}$ - the coordinate of the lifting mechanism; $x_{2}$ - the coordinate of suspension; $\varphi$ - the rotation angle of the drum of the lifting mechanism multiplied by the repeatability of the rope of the lifting mechanism; $m_{0}$ - the mass of the metal structure; $m_{2}$ - the mass of the lifted cargo; $I$ - the moment of the inertia of the rotating parts of the lifting mechanism; $R$ - the radius of the drum of the lifting mechanism; $k_{0}$ - the stiffness of the metal structure of the crane in the vertical direction; $k$ - the stiffness of the rope; $h_{0}$ - the damping coefficient of the metal structure; $h$ - the damping coefficient of the rope.

The mass of the first crane is $4080 \mathrm{~kg}$ and the mass of the second crane is $8700 \mathrm{~kg}$. In the course of the computation, it was found that $I=1.5 \cdot 10^{3} \mathrm{~kg} \cdot \mathrm{m}^{2}$ and damping coefficient $h=0.225 \cdot 10^{3} \mathrm{~kg} / \mathrm{s}$ for both cranes;
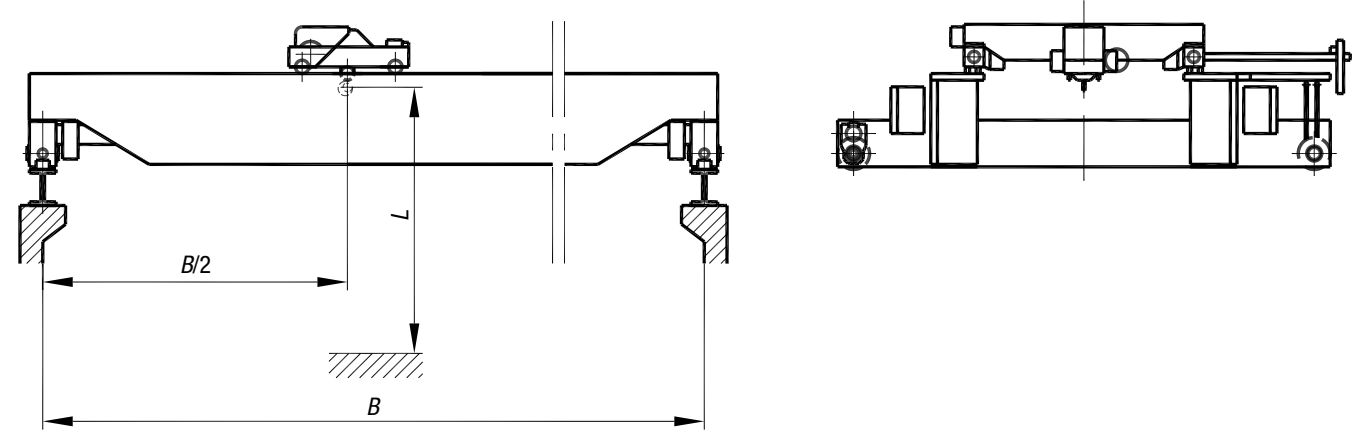

Fig. 1. The scheme of an overhead crane 


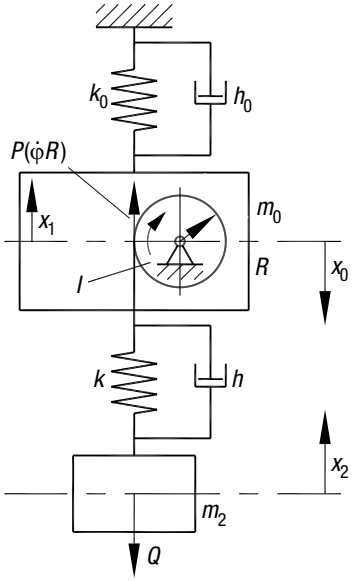

Fig. 2. The dynamic model of an overhead crane

for the first crane $-h_{0}=17.56 \cdot 10^{3} \mathrm{~kg} / \mathrm{s}$ and for the second one $-13.98 \cdot 10^{3} \mathrm{~kg} / \mathrm{s}$.

The stiffness of the metal structure of the crane was established with reference to the value of static deflection on lifting the maximum cargo. In the case of the first crane, deflection equals $17 \mathrm{~mm}$, whereas in the case of the second one $-31 \mathrm{~mm}$. Thus, $k_{0}$ for the first crane equals $7.35 \cdot 10^{6} \mathrm{~N} / \mathrm{m}$ and for the second one $3.22 \cdot 10^{6} \mathrm{~N} / \mathrm{m}$.

Because the stiffness of the rope impacts the dynamics of the crane, the formed mathematical model was discussed upon for each crane using two values of the length $L$ of the unwind rope: when the length of the rope is maximum and equals the maximum height of lifting and when $L$ equals a half of the maximum height of lifting. The stiffness of the rope depends on its tension, and the initial value of stiffness equals a small part of stiffness upon the maximum load:

$$
k_{\max }=\frac{E \cdot A}{L},
$$

where: $E$ - the modulus of the stiffness of the wire of the rope; $A$ - the area of the cross-section; $L$ - the length of the rope.

The dependence of stiffness $k_{1}$ on the rope is approximated by the curve shown in Fig. 3, and the values of individual parameters are provided in the Table.

When the expressions of potential and kinetic energy as well as the dissipation function (1) are inserted in the Lagrange's equations of the second type, a system of three equations is obtained and expressed in operator notation, thus obtaining solutions to the formation of

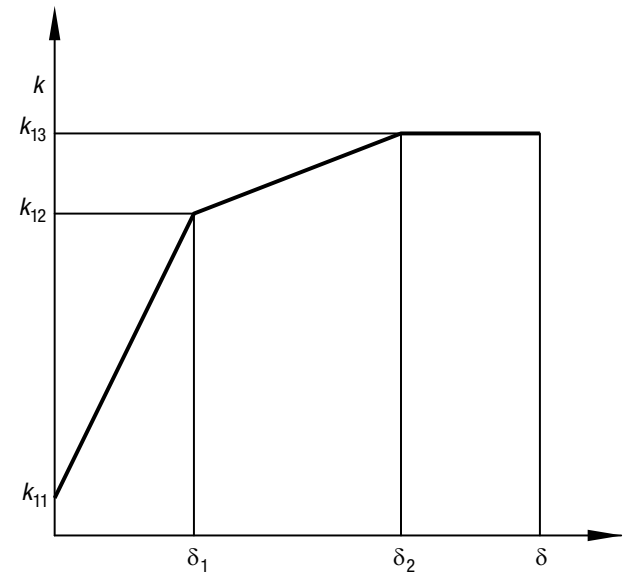

Fig. 3. The curve of the stiffness of the rope

the Simulink-model in the environment of the MATLAB software package. It is supposed that the rotational speed of the engine is constant and is computed on the basis of the given lifting speed upon assessing the repeatability of the pulley system. The obtained results of solutions are used for optimizing the structure of the crane and parameters of its control equipment.

\section{Results of Research Work}

In the course of research work, it was found that when starting the engine of the lifting mechanism, considerable dynamic loads affecting the mechanism appeared (Fig. 4).

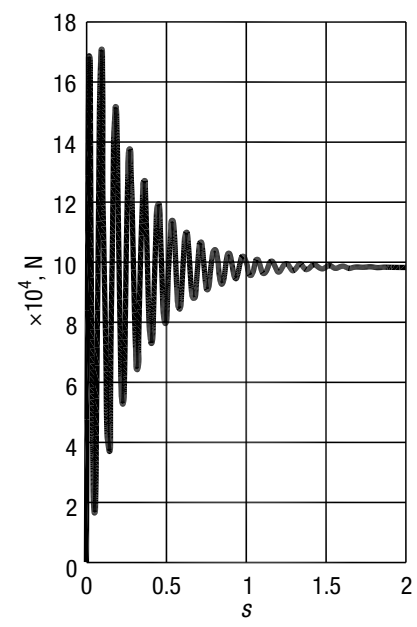

Fig. 4. The time diagram of the force having an impact on the lifting mechanism (crane 2, rope length $L=6 \mathrm{~m}$ )

Table. The parameters of the stiffness of the rope

\begin{tabular}{cccccccc}
\hline Crane & Lentgh of the rope $L(\mathrm{~m})$ & $\delta_{1}(\mathrm{~mm})$ & $\delta_{2}(\mathrm{~mm})$ & $k_{11}\left(10^{6} \mathrm{~N} / \mathrm{m}\right)$ & $k_{12}\left(10^{6} \mathrm{~N} / \mathrm{m}\right)$ & $k_{13}\left(10^{6} \mathrm{~N} / \mathrm{m}\right)$ \\
\hline 1 & 6 & 11 & 49 & 0.58 & 9.33 & 11.67 \\
\hline 2 & 3 & 6 & 85 & 1.16 & 18.60 & 22.32 \\
\hline & 10 & 34 & 104 & 0.28 & 4.46 & 5.60 \\
\hline
\end{tabular}


Independently of the length of the rope, vibrations appearing in this zone are practically harmonic for both cranes and have a frequency of $11 \div 12 \mathrm{~Hz}$. Within the first period, the dynamic factor is:

$$
K_{d}=\frac{F_{\max }}{F_{s}},
$$

where: $F_{\max }$ - maximum affecting force; $F_{s}$ - the gravity force of the lifted cargo; the value of the factor is 1.7. Such vibrations disappear within $1.8 \div 2.0$ seconds.

Hence, in the beginning of the lifting process, the above-mentioned $12 \mathrm{~Hz}$ vibrations are transferred to suspension (Fig. 5a) upon the impact of the force of the inertia of cargo and the force of the stiffness of the rope; however, such vibrations disappear within several periods, i.e. within $0.4 \div 0.5$ seconds. Simultaneously, vibrations of a considerably lower frequency of $2.5 \div 2.8 \mathrm{~Hz}$ appear and disappear within the period of $7 \div 8$ seconds from the beginning of the lifting process. An exception is provided in the case of the second crane when the length of the rope is not big and equals $3 \mathrm{~m}$. In this example (Fig. 5b), vibrations within the first 4 seconds are sharply biharmonic and consist of frequency harmonics of $11 \mathrm{~Hz}$ and $2.5 \mathrm{~Hz}$.

Vibrations of the same frequency may also appear in the metal structure of the crane (Fig. 6) and their frequency makes about $2.5 \div 2.8 \mathrm{~Hz}$. In the first period, the dynamic factor equals 1.15 . This gradually falling load exists for 3 seconds, i.e. $6 \div 7$ periods. In addition, an inconsiderable variable load of higher frequency $(11 \div 12 \mathrm{~Hz})$ expresses itself in the first period.

a)

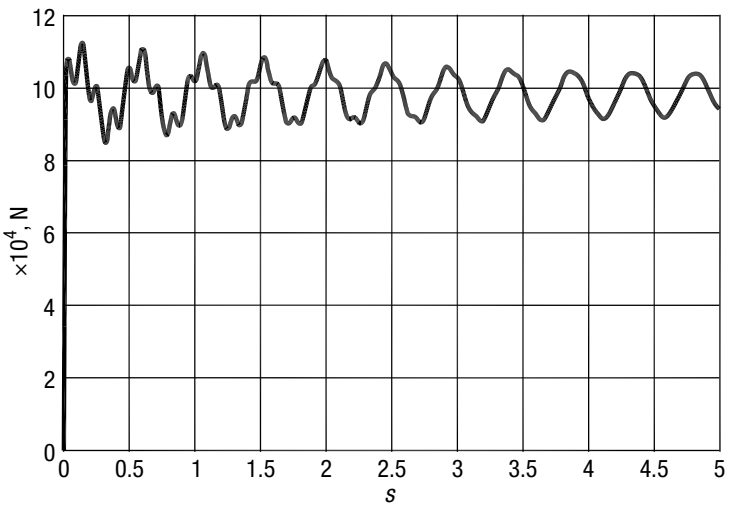

b)

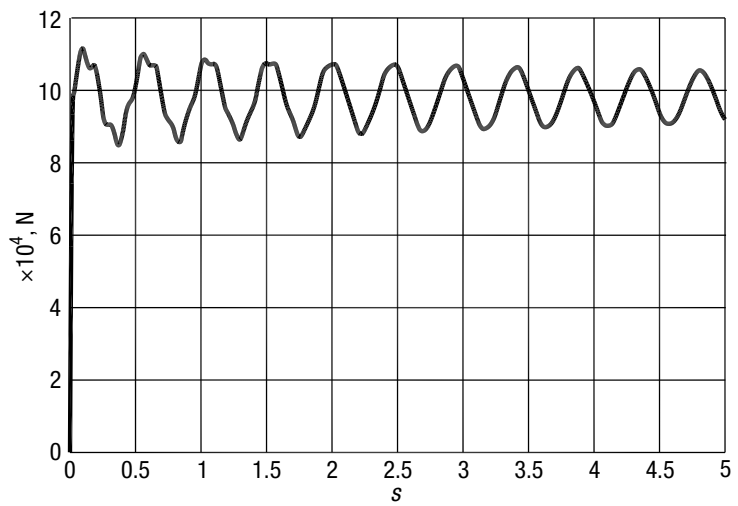

Fig. 5. The time diagram of the force that affects the end of the rope, crane $2: \mathrm{a}-L=6 \mathrm{~m} ; \mathrm{b}-L=3 \mathrm{~m}$

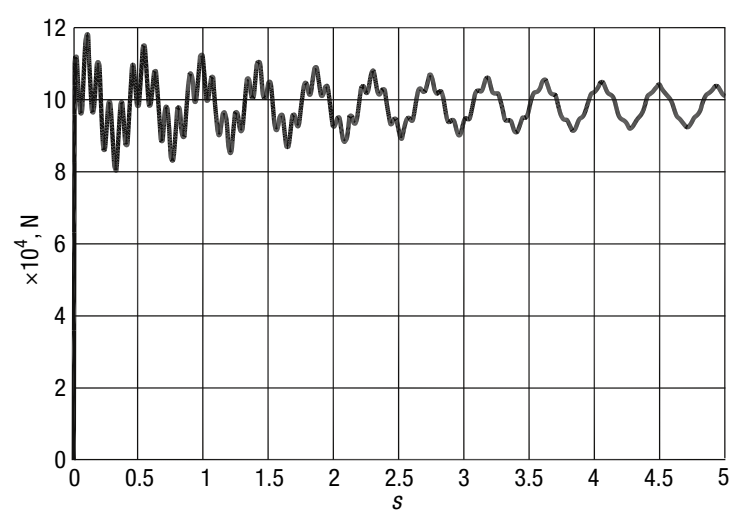

Fig. 6. The time diagram of the load of the metal structure of the crane (the crane $2, \mathrm{~L}=6 \mathrm{~m}$ )

\section{Conclusions}

1. On starting the engine of the lifting mechanism, dynamic loads of a frequency of $11 \div 12 \mathrm{~Hz}$ affect the rope. The gradually falling impact of the loads lasts for up to 2 seconds. In the first period of vibrations, the dynamic load is equal to about 0.7 of the static load caused by the gravity force of the lifted cargo. The introduced dynamic load slightly depends on the length of the rope.

2. An inconsiderable part of the dynamic load appearing in the lifting mechanism is transferred to the suspension via the rope; however, dynamic loads of lower frequencies $(2.5 \div 2.8 \mathrm{~Hz})$ also appear and exist for $7 \div 8$ seconds.

3. The dynamic loads of lower frequencies affect the metal structure. In the first period, the dynamic factor equals 1.15 .

\section{References}

Augustaitis, V. K; Gičan, V.; Iljin, I.; Šešok, N.; Geleževičius, V. 2006. Model of a multi-sectional web offset printing press drive section, controlled by electronic shaft, Solid State Phenomena 113: 103-108.

doi:10.4028/www.scientific.net/SSP.113.103

Bakšys, B.; Ramanauskyte, K.; Povilionis, A. B. 2009. Vibratory manipulation of elastically unconstrained part on a horizontal plane, Mechanika (1): 36-41.

Bogdevičius, M.; Vika, A. 2005. Investigation of the dynamics of an overhead crane lifting process in a vertical plane, Transport 20(5): 176-180.

Dyakov, I.; Prentkovskis, O. 2008. Optimization problems in designing automobiles, Transport 23(4): 316-322. doi:10.3846/1648-4142.2008.23.316-322

Imanishi, E.; Nanjo, T.; Kobayashi, T. 2009. Dynamic simulation of wire rope with contact, Journal of Mechanical Science and Technology 23(4): 1083-1088. doi:10.1007/s12206-009-0345-0

Gichan, V.; Slivinskas, K.; Augustaitis, V. K. 2008. Research of force drives of the production gear hobbing machine with CNC, Mechanika (2): 43-47.

Gottvald, J. 2010. The calculation and measurement of the natural frequences of the bucket wheel excavator SCHRS 1320/4X30, Transport 25(3): 269-277. doi:10.3846/transport.2010.33 
Ju, F.; Choo, Y. S.; Cui, F. S. 2006. Dynamic responses of tower crane induced by the pendulum motion of the payload, International Journal of Solids and Structures 43(2): 376-389. doi:10.1016/j.ijsolstr.2005.03.078

Kaczmarczyk, S.; Ostachowicz, W. 2003. Transient vibration phenomena in deep mine hoisting cables. Part 1: Mathematical model, Journal of Sound and Vibration 262(2): 219-244. doi:10.1016/S0022-460X(02)01137-9

Oguamanam, D. C. D.; Hansen, J. S.; Heppler, G. R. 1998. Dynamic response of an overhead crane system, Journal of Sound and Vibration 213(5): 889-906.

doi:10.1006/jsvi.1998.1564

Piette, A.; Malchaire, J. 1992. Technical characteristics of overhead cranes influencing the vibration exposure of the operators, Applied Ergonomics 23(2): 121-127. doi:10.1016/0003-6870(92)90084-9

Slivinskas, K.; Gichan, V.; Striška, V.; Poška, A. J. 2010. Optimization of transport movement parameters of the transfer manipulator for the quenching bath according to the technological process requirements, Solid State Phenomena 164: 411-418. doi:10.4028/www.scientific.net/SSP.164.411

Sochacki, W. 2007. The dynamic stability of a laboratory model of a truck crane, Thin-Walled Structures 45(10-11): 927-930. doi:10.1016/j.tws.2007.08.023

Verdeş, D.; Stan, S.-D.; Bălan, R.; Coman, M. 2010. Study of design, kinematics and virtual control of 4 degrees of freedom parallel robot, Mechanika (2): 70-74.

Wu, J.-J. 2004. Dynamic response of a three-dimensional framework due to a moving carriage hoisting a swinging object, International Journal for Numerical Methods in Engineering 59(13): 1679-1702. doi:10.1002/nme.916 